\title{
Skull Anatomic Landmarks for Retrosigmoid Craniotomy in a Chinese Cohort: A 3D-Computed Tomography Study in Vivo
}

\author{
Bing FANG, Gao CHEN, Lin WANG, Xiangdong ZHU, Qiang HU, Jianmin ZHANG \\ The Second Affiliated Hospital of Zhejiang University, School of Medicine, Department of Neurosurgery, Hangzhou, China
}

\section{ABSTRACT}

AIM: This study was designed to determine the anatomic position of the asterion and the relationship between the asterion and the transverse sigmoid sinus junction (TSSJ) in a Chinese cohort.

MATERIAL and METHODS: Venous computed tomography (CT) angiography was performed in 32 patients to simultaneously obtain 3D-CT volume rendering images of the cranial bone and the dural sinus. The relationship between the TSSJ and the asterion was analyzed.

RESULTS: The distance from the asterion to root of zygoma (ROZ) was $54.6 \pm 5.50 \mathrm{~mm}$ on the right side and $54.1 \pm 5.42 \mathrm{~mm}$ on the left side. The asterion was $49.10 \pm 3.56 \mathrm{~mm}$ above the tip of mastoid process (TOP) on the right side and $48.70 \pm 2.23 \mathrm{~mm}$ on the left side. The asterion's position was at the junction of the transverse-sigmoid sinus complex in 44 cases, below it in 19 cases, and above it in one case.

CONCLUSION: 3D-CT volume rendering imaging is capable of accurately and simultaneously visualizing the bony landmark and the dural sinus structure outline in vivo, thus offering a new option for anatomic research and morphometric investigation. The accurate location of asterion can be found using the root of the zygoma and the tip of the mastoid process.

KEYWORDS: Transverse-sigmoid sinus, Retrosigmoid craniotomy, Asterion, Three-dimensional computed tomography

\section{INTRODUCTION}

The correct location of an initial strategic burr hole for a retrosigmoid craniotomy to give access to the cerebellopontine angle (CPA) is paramount in obtaining optimal exposure in this region (12).

As the transverse and sigmoid sinuses are the natural limits of these exposures, a knowledge about their cranial topography constitutes the main factor in the planning of these retrosigmoid approaches (10). The asterion serves as the junction of the lambdoid, parietomastoid and occipitomastoid sutures, and has been used in retrosigmoid craniotomy to locate the transverse-sigmoid sinus junction $(2,9,12-14)$.

As cadaveric studies have shown considerable variability in the relationship of the asterion to the underlying venous structures and its population-specific variability, its validity as a surgical landmark has been questioned (8). Recent advances in 3D-computed tomography (CT) volume rendering techniques have made it possible to visualize minute bone sutures and venous structures of the posterior fossa $(3,5,6$, 11).

The purpose of this study is to determine the anatomic position of the asterion and the transverse-sigmoid sinus junction in Chinese population using the root of the zygoma and the tip of the mastoid process as palpable points. We also tried to clarify the relationship between the asterion and the inferior aspect of the transverse-sigmoid sinus junction using a 3DCT procedure in vivo (8).

\section{MATERIAL and METHODS}

The Zhejiang University ethics committee approval to fulfill the 
informed consent procedure research object. Using a duralenergy CT scanner (Somatom Definition; Siemens Healthcare, Erlangen, Germany), 32 patients (23 male and 9 female; mean age 56 years, range 21-87 years) underwent high-resolution CT scans in combination with venous angiography. The CT parameters in the dual-energy mode were 140 and $80 \mathrm{kV}$ tube voltage at 51 and 360 effective mAs, 0.5 second rotation time, collimation of $64 \times 0.6 \mathrm{~mm}$ with z-flying focal spot, and pitch of 0.6. The 140 and $80 \mathrm{kV}$ images (dual-energy images) were reconstructed separately in sections that were $0.75 \mathrm{~mm}$ wide at $0.5 \mathrm{~mm}$ increments with a D30 kernel, for a field of view of $180 \mathrm{~mm}^{2}$. The contrast-enhanced CT scan in the dual-energy mode was obtained with a $4.0 \mathrm{~mL} / \mathrm{s}$ injection of $80 \mathrm{ml}$ nonionic contrast medium (Ultravist $300 \mathrm{mg} \mathrm{l} / \mathrm{ml}$, Bayer Schering Pharma) followed by $30 \mathrm{ml}$ saline solution into the cubital vein through an 18-gauge catheter after a patient-specific delay determined by a bolus test (28-37s) (15). The images were transferred to a workstation (MultiModality Workplace, Siemens Healthcare), and prototype software (Syngo 2008G, Siemens Healthcare) was used to generate $3 D$ images by volume render (VR) (15). The procedure for projecting the sinus complex onto the bone surface consisted of two steps. First, the transverse-sigmoid sinus complex that was easily identified on the bone removal venous CT angiography (CTV) images was marked and outlined with a number of points (Figure 1A-D). Second, the outline of the transverse- sigmoid sinus complex was visualized on the bone surface by returning to the skull 3D images (Figure 1A-D). The distance from the asterion to the root of zygoma (A-ROZ) and the tip of the mastoid process (A-TMP), was measured on the skull $3 \mathrm{D}$ images in the workstation, measurements were taken (8) (Figure 1A-D). The position of the asterion was determined as being over the transverse- sigmoid sinus complex, above it (over supratentorial dura) or below it (over posterior fossa dura) (Figure 2A-C). Data obtained were analysed using the statistical package software (SPSS version 12.0, SPSS)(8). Side and gender differences were assessed by Student's $t$ test. A p values $\leq 0.05$ was considered statistically significant.

\section{RESULTS}

\section{Position of the Asterion from ROZ and TMP:}

Table I shows the mean and standard deviation (SD) of the two measurements of the asterion in different genders and on different sides. There was no statistically significant difference in side difference. With respect to gender difference, the asterion in males was significantly higher than that in females.

\section{Relationship between the Asterion and the Transverse- Sigmoid (T-S) Sinus Complex:}

The asterion was located on the T-S sinus complex in 44
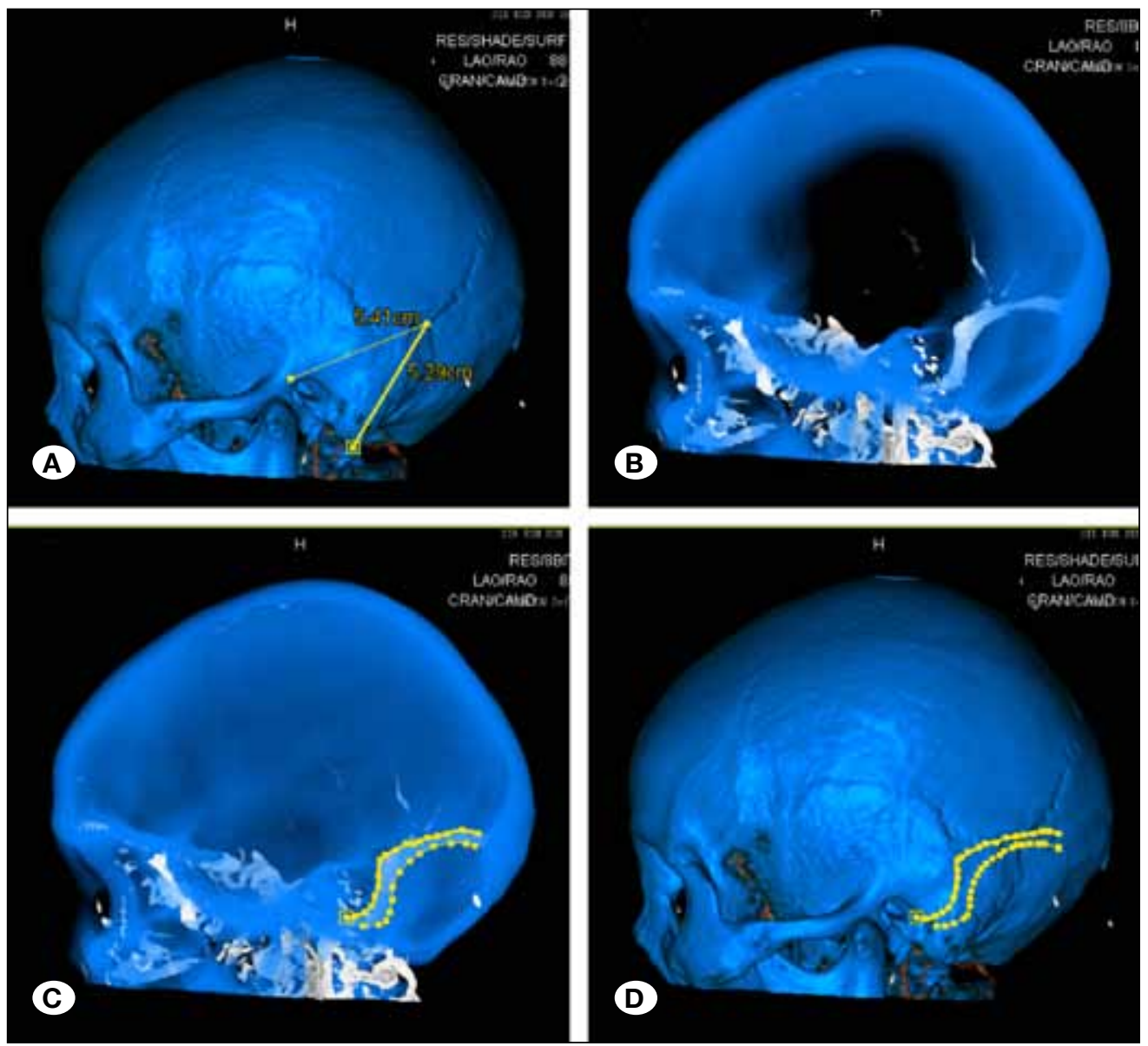

Figure 1: The distance from the asterion to $\mathrm{ROZ}$ and the distance from the asterion to TMP measured on the CT post processor (A). The transversesigmoid sinus complex on CTV imaging (B). The transversesigmoid sinus complex marked by the dotted line (C). Projection of the dotted line marker of the transverse-sigmoid sinus complex on the surface of the skull (D). 
cases. The asterion was below the T-S sinus complex (over the posterior fossa dura mater) in 19 cases, and above the T-S sinus complex (over the supratentorial dura mater) in only one case. (Table II) The inferior aspect of TSSJ was located anterior to the asterion. The distance between the asterion and the inferior aspect of the TSSJ was $18.25 \pm 3.32 \mathrm{~mm}$ on the right side and $17.43 \pm 3.95 \mathrm{~mm}$ on the left side. There was no statistically significant side difference $(p \geq 0.05)$.

\section{- DISCUSSION}

Retrosigmoid craniotomy is the most commonly used approach to gain access to the CPA, but it is often limited by the transverse and sigmoid sinuses. Correct location of the burr hole, especially the initial burr hole, is crucial to avoid venous injury and obtain optimal exposure $(1,10,14)$. Classically, the asterion has been cited as an external landmark for the TSSJ. However, its position cannot be discerned because it is covered by the scalp (13). In this study, we used the root of the zygoma and the tip of the mastoid as the palpable landmarks to locate the asterion. Mwachaka et al. $(8,13)$ found that in Kenyans the distance from the asterion to the root of zygoma was $58.85 \pm 2.50 \mathrm{~mm}$ on the right side and $58.44 \pm 2.12 \mathrm{~mm}$ on the left side, and the distance from the asterion to the tip of the mastoid process was $47.89 \pm 3.72 \mathrm{~mm}$ the distance from the asterion and $47.62 \pm 2.87 \mathrm{~mm}$ on the left side, while the in Turks the corresponding fugure was $54.6 \pm 5.50 \mathrm{~mm}$ and $54.1 \pm 5.42 \mathrm{~mm}$, and $49.10 \pm 3.56 \mathrm{~mm}$ and $48.70 \pm 2.23$ $\mathrm{mm}$ (13). These studies show that the location of the asterion is different in different races and populations. However, the measurements of the above studies were based on cadaveric specimens.

Current advances in image-rendering have made it possible to generate $3 \mathrm{D}$ models by reconstructing image data and perform precise morphometric investigation in vivo $(3,5,6$, 11). Using 64 bilateral measurements obtained in 32 Chinese patients, we performed a morphometric study on the location of the asterion. The results showed that in Chinese the distance from the asterion to the root of zygoma was 54.6 $\pm 5.50 \mathrm{~mm}$ on the right and $54.1 \pm 5.42 \mathrm{~mm}$ on the left side, and the distance from the asterion to the tip of the mastoid process was $49.10 \pm 3.56 \mathrm{~mm}$ on the right side and $48.70 \pm$ $2.23 \mathrm{~mm}$ on the left side. Day et al. (4) found that the asterion was over the posterior fossa dura in $32 \%$ of their samples on the right and $25 \%$ on the left. Its position was over the transverse or sigmoid sinus complex in $61 \%$ of the right sides and $66 \%$ of the left sides (12).

Martinez et al. reported that the asterion was over the transverse sinus in $87.8 \%$ of their cases (7). In our study, we found that the asterion was located over the transverse sigmoid sinus complex in $69 \%$ cases, which is consistent with these studies (7). But the TSSJ is the point of the posterior and inferior aspect of the knee (upper genu) between the sigmoid and transverse sinuses, which is paramount in obtaining optimal exposure in CPA (14).

Table I: Position of the Asterion from the Root of the Zygoma (ROZ) and the Tip of Mastoid (TMP)

\begin{tabular}{ccccccc}
\hline & Male & Female & p-value & Left & Right & p-value \\
\hline ROZ $(\mathrm{mm})$ & $55.88 \pm 2.80$ & $52.52 \pm 2.52$ & 0.000 & $54.59 \pm 3.34$ & $54.75 \pm 2.97$ & 0.827 \\
\hline TMP $(\mathrm{mm})$ & $51.52 \pm 3.94$ & $48.82 \pm 3.43$ & 0.005 & $50.69 \pm 4.35$ & $50.40 \pm 3.59$ & 0.758 \\
\hline
\end{tabular}

Table II: Relationship between the Asterion and the Transverse-Sigmoid Sinus Complex (TSSC)

\begin{tabular}{ccccc}
\hline & Male & Female & Left & Right \\
\hline Above TSSC & 1 & 0 & 1 & 0 \\
\hline At the TSSC & 33 & 11 & 21 & 23 \\
\hline Below the TSSC & 12 & 7 & 10 & 32 \\
\hline Total & 46 & 18 & 32 & 32 \\
\hline
\end{tabular}
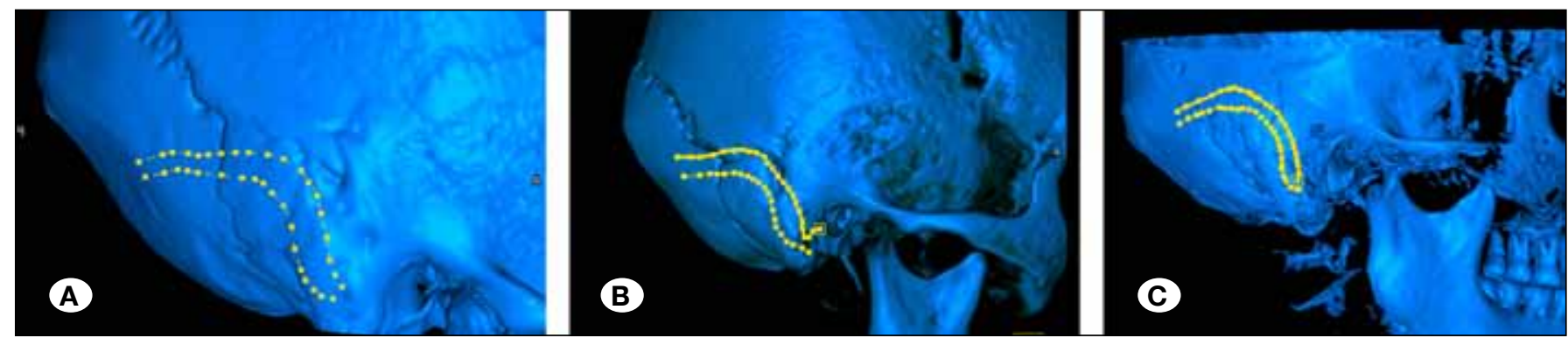

Figure 2: Relationship between the asterion and the transverse-sigmoid complex. (A) above TSSC; (B) at TSSC; (C) below TSSC. 
Once it is known where the junction is, the initial drilling is carried out approximately $1 \mathrm{~cm}$ lower and medial to this point (12). By the two-step procedure, we projected the sinus complex onto the bone surface to investigate the relation between the asterion and the TSSJ. It was found that the TSSJ was located about $1.8 \mathrm{~cm}$ anterior to the asterion, which is similar to Ribas's finding that the junction of the transverse and sigmoid sinus was $1 \mathrm{~cm}$ anterior to the asterion across the parietomastoid suture $(10,12)$.

\section{CONCLUSIONS}

3D-CT volume rendering imaging is capable of accurately and simultaneously visualizing the bony landmark and the dural sinus structure outline in vivo, thus offering a new option for anatomic research and morphometric investigation. The asterion can be located accurately using the root of the zygoma and the tip of the mastoid process. The inferior aspect of the transverse-sigmoid sinus junction is located 1.8 $\mathrm{cm}$ anterior to the asterion.

\section{- REFERENCES}

1. Ahlhelm F, Nabhan A, Naumann N, Grunwald I, Shariat K, Reith W: Skull base tumors. Radiologe 45(9): 807-815, 2005

2. Bozbuga M, Boran BO, Sahinoglu K: Surface anatomy of the posterolateral cranium regarding the localization of the initial burr-hole for a retrosigmoid approach. Neurosurg Rev 29(1): 61-63, 2006

3. da Silva EB Jr, Leal AG, Milano JB, da Silva LF Jr, Clemente RS, Ramina R: Image-guided surgical planning using anatomical landmarks in the retrosigmoid approach. Acta Neurochir (Wien) 152(5):905-910, 2010

4. Day JD, Tschabitscher M: Anatomic position of the asterion. Neurosurgery 42(1):198- 199, 1998

5. Gharabaghi A, Rosahl SK, Feigl GC, Liebig T, Mirzayan JM, Heckl S, Shahidi R, Tatagiba M, Samii M: Image-guided lateral suboccipital approach: Part 1-individualized landmarks for surgical planning. Neurosurgery 62(3) Suppl 1: 18-22, 2008
6. Hamasaki T, Morioka M, Nakamura H, Yano S, Hirai T, Kuratsu $\mathrm{J}$ : A 3-dimensional computed tomographic procedure for planning retrosigmoid craniotomy. Neurosurgery 64(5) Suppl 2: 241-245, 2009

7. Martinez F, Laxague A, Vida L, Prinzo H, Sgarbi N, Soria VR, Bianchi C: Topographic anatomy of the asterion. Neurocirugia (Astur) 16(5):441-446, 2005

8. Mwachaka PM, Hassanali J, Odula PO: Anatomic position of the asterion in Kenyans for posterolateral surgical approaches to cranial cavity. Clin Anat 23(1):30-33, 2010

9. Oishi M, Fukuda M, Saito A, Hiraishi T, Fuji Y: Presurgical evaluation for lateral suboccipital craniotomy using contrastenhanced CT volumetric imaging. No Shinkei Geka 37(5): 459-465, 2009

10. Ribas GC, Rhoton AL Jr, Cruz OR, Peace D: Suboccipital burr holes and craniectomies. Neurosurg Focus 19(2):E1, 2005

11. Sheng B, Lv F, Xiao Z, Ouyang Y, Deng J, You Y, Liu N: Anatomical relationship between cranial surface landmarks and venous sinus in posterior cranial fossa using CT angiography. Surg Radiol Anat 34(8):701-708, 2012

12. Tubbs R S, Loukas M, Shoja M M, Bellew M P, Cohen-Gadol A $A$ : Surface landmarks for the junction between the transverse and sigmoid sinuses: Application of the "strategic" burr hole for suboccipital craniotomy. Neurosurgery 65 Suppl 6: 37-41, 2009

13. Ucerler H, Govsa F: Asterion as a surgical landmark for lateral cranial base approaches. J Craniomaxillofac Surg 34(7):415420, 2006

14. Urculo E, Alfaro R, Arrazola M, Rejas G, Proano J, Igartua J: Anatomical landmarks and surgical limits in the suboccipital transmeatal approach to the acoustic neuroma. Neurocirugia (Astur) 14(2):107-115, 2003

15. Zhang LJ, Wu SY, Niu JB, Zhang ZL, Wang HZ, Zhao YE, Chai X, Zhou CS, Lu GM: Dual-energy CT angiography in the evaluation of intracranial aneurysms: Image quality, radiation dose, and comparison with 3D rotational digital subtraction angiography. AJR Am J Roentgenol 194(1):23-30, 2010 